\title{
THE RECUPERATIVE HEAT EXCHANGERS - THE MEAN TEMPERATURE DIFFERENCE IN THE SPECIAL CASES OF HEAT TRANSFER
}

\author{
GUŽELA Štefan ${ }^{1 a}$, DZIANIK František ${ }^{1 b}$ \\ ${ }^{1}$ Slovak University of Technology in Bratislava, Faculty of Mechanical Engineering, Institute of Process \\ Engineering, Nám. slobody 17, 81231 Bratislava, Slovakia, \\ e-mail: ${ }^{\mathrm{a}}$ stefan.guzela@stuba.sk, brantisek.dzianik@stuba.sk
}

\begin{abstract}
The heat exchangers are used to heat or cool the material streams. To calculate the heat exchanger, it is important to know the type of heat exchanger and its operating characteristic. This characteristic determines one of the key variables (e.g., $F$, NTU $\mathrm{min}_{\text {, or }} \theta$ ). In some special cases, it is not necessary to know its operating characteristic to calculate the heat exchanger. This article deals with these special cases. The article also contains a general dependency that allows checking the key variables related to a given heat exchanger.
\end{abstract}

KEYWORDS: Recuperative heat exchanger, number of transfer units, operating characteristic, heat efficiency

\section{Introduction}

The calculation of heat exchangers can be carried out by various methods. LMTD method [1], $\varepsilon$-NTU method [2], $\theta-N T U$ method [3], and Roetzel-Spang method [4] belong among the best known. From a practical point of view, $\varepsilon$-NTU method is considered to be one of the most important methods because it allows performing not only the design calculation but also the checking (verification) calculation of the exchanger. This method also allows indirectly determining the value of $\overline{\Delta T}$ (i.e., $\overline{\Delta T}=P_{\min \mathrm{B}}\left(T_{h 1}-T_{c 1}\right)$, Fig. 1). However, $\varepsilon$-NTU method primarily determines the value of $\mathrm{NTU}_{\min }$ which is a function of the variables $P_{\text {min }}$ (also referred to as $\varepsilon$, i.e., $P_{\min }=\varepsilon$ ) and $R_{\text {min. }}$. Other methods also enable using so-called operating characteristics, primarily for determining the variables $F$ and $\theta$. The key variables allow specifying the variable $\overline{\Delta T}$. The purpose of this article is, inter alia, to show how $\overline{\Delta T}$ can be determined in certain specific cases.

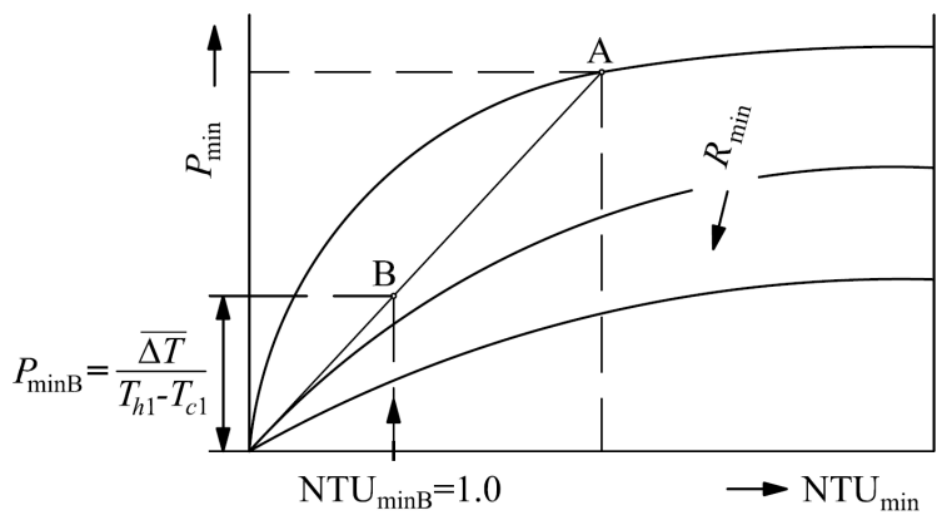

Fig. 1 The schematic representation of the diagram $\varepsilon$-NTU.

Generally, for variables within heat exchangers, the subscript min is attributed to a weaker stream. The heat exchanger stream having a lower mean heat capacity, i.e., $\bar{C}_{p \min }=\min \left\{\bar{C}_{p h}, \bar{C}_{p c}\right\}$, is considered a weaker stream. The subscripts $h$ and $c$ represent 
the individual material streams (Fig. 2 and 5). However, it should be noted that the subscript min is usually also replaced by subscript 1 (i.e., $\bar{C}_{p \min }=\bar{C}_{p 1}, P_{1}=P_{\min }, R_{1}=R_{\min }$, $\mathrm{NTU}_{1}=\mathrm{NTU}_{\text {min }}$ ). If the subscript 1 denotes a weak stream, the variable $P_{1}$ is identical with the variable $\Phi$ (i.e., $P_{1}=\Phi$ ) which represents the heat efficiency of the exchanger [5].

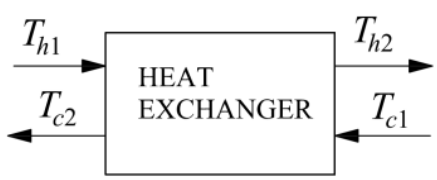

a) Schematic representation.

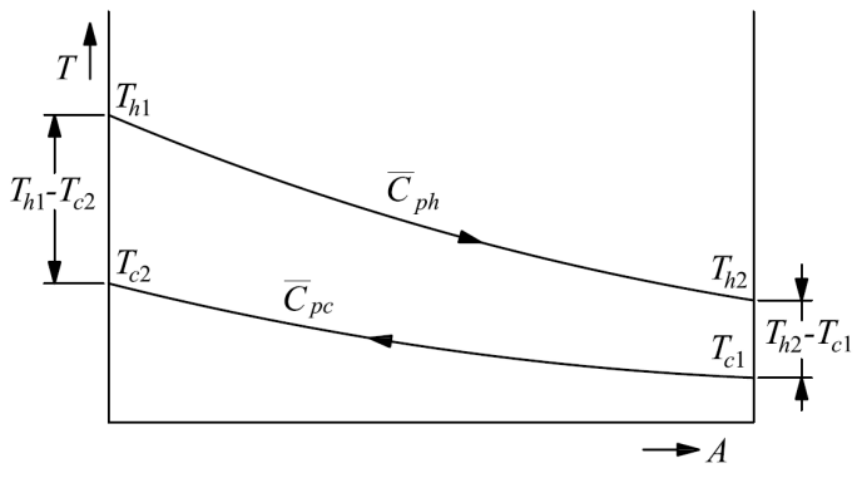

b) Temperature profile.

Fig. 2 The schematic representation of the double-tube countercurrent heat exchanger.

The dependence in Fig. 1, also called the operational characteristic, is usually determined on the basis of results of the experimental measurements. If such dependence has been created correctly, the values determined by it should also correspond to the general equations that follow from the dimensionless variables describing the heat exchanger. The paper also presents a general equation (as well as a general graphical dependence) which can be used to check whether the operational characteristic of a given heat exchanger has been created correctly.

\section{Relationships among the dimensionless variables}

The variables mentioned in the previous section are interrelated. Based on [6] and [7], this relationship can be expressed by the following equation:

$$
\begin{aligned}
& \theta=\frac{\overline{\Delta T}}{T_{h 1}-T_{c 1}}=\frac{F \Delta T_{\mathrm{ln}}}{T_{h 1}-T_{c 1}}=\frac{P_{\text {min }}}{\mathrm{NTU}_{\text {min }}}=\frac{F P_{\text {min }}\left(1-R_{\text {min }}\right)}{\ln \left[\left(1-R_{\text {min }} P_{\text {min }}\right) /\left(1-P_{\text {min }}\right)\right]} \text {, where } \\
& P_{\min }=\left(T_{\min 2}-T_{\min 1}\right) /\left(T_{\max 1}-T_{\min 1}\right), \text { while } P_{\min } \in\langle 0.0 ; 1.0\rangle, \\
& R_{\min }=\bar{C}_{p \min } / \bar{C}_{p \max }=\left(T_{\max 1}-T_{\max 2}\right) /\left(T_{\min 2}-T_{\min 1}\right), \text { while } R_{\min } \in\langle 0.0 ; 1.0\rangle, \\
& \mathrm{NTU}_{\text {min }}=\bar{k} A / \bar{C}_{p \text { min }}, \text { while } \mathrm{NTU}_{\text {min }} \in\left\langle\mathrm{NTU}_{\min C} ; \mathrm{NTU}_{\text {min } C O}\right\rangle, \\
& \Delta T_{\mathrm{ln}}=\left[\left(T_{h 1}-T_{c 2}\right)-\left(T_{h 2}-T_{c 1}\right)\right] / \ln \left[\left(T_{h 1}-T_{c 2}\right) /\left(T_{h 2}-T_{c 1}\right)\right] .
\end{aligned}
$$

In these equations, i.e., Eqs. (2) and (3), the subscript max represents a variable associated with a stronger stream. This index is usually also replaced by index 2.A stream whose mean heat capacity is greater, i.e., $\bar{C}_{p \max }=\bar{C}_{p 2}=\max \left\{\bar{C}_{p h}, \bar{C}_{p c}\right\}$, is always considered a stronger stream. Eq. (5) determines the maximum possible value of the variable $\overline{\Delta T}$ that a heat exchanger can achieve. In the case of the double-tube countercurrent heat exchanger, the following always applies: $\overline{\Delta T}=\Delta T_{\ln }$. This does not apply to other heat exchangers, 
which is the reason why these heat exchangers are compared with the double-tube countercurrent heat exchanger. It can further be noted that Eq. (5) may also be written in the form:

$$
\begin{gathered}
\frac{\Delta T_{l n}}{T_{h 1}-T_{c 1}}=\frac{\left(R_{c}-1\right) P_{c}}{\ln \left(\frac{1-P_{c}}{1-P_{c} R_{c}}\right)}=\frac{\left(1-R_{h}\right) P_{h}}{\ln \left(\frac{1-R_{h} P_{h}}{1-P_{h}}\right)}=\frac{\left(1-R_{i}\right) P_{i}}{\ln \left(\frac{1-R_{i} P_{i}}{1-P_{i}}\right)}, \text { where } \\
R_{c}=\bar{C}_{p c} / \bar{C}_{p h}=\left(T_{h 1}-T_{h 2}\right) /\left(T_{c 2}-T_{c 1}\right)=1 / R_{h}, \\
P_{h}=\left(T_{h 1}-T_{h 2}\right) /\left(T_{h 1}-T_{c 1}\right) \text { a } P_{c}=\left(T_{c 2}-T_{c 1}\right) /\left(T_{h 1}-T_{c 1}\right) .
\end{gathered}
$$

The meaning of temperatures in these equations is shown in Fig. 2 and 5. The ratio value $\Delta T_{l n} /\left(T_{h 1}-T_{c 1}\right)$ may also be determined by Fig. 3. However, it is preferable to work with Fig. 4 to determine the value of the ratio LMTD $/ \Delta T_{\text {larger }}$. The dependence shown in this figure results from the following equation:

$$
\frac{\mathrm{LMTD}}{\Delta T_{\text {larger }}}=\frac{\left[1-\Delta T_{\text {smaller }} / \Delta T_{\text {larger }}\right]}{\ln \left[1 /\left(\Delta T_{\text {smaller }} / \Delta T_{\text {larger }}\right)\right]}, \text { while } \Delta T_{\text {smaller }} \leq \Delta T_{l \text { arger }} .
$$

In this equation, LMTD represents the logarithmic mean temperature difference for the double-tube countercurrent and the double-tube cocurrent heat exchanger. In the case of the double-tube countercurrent heat exchanger, $\Delta T_{\text {smaller }}$ and $\Delta T_{\text {larger }}$ are replaced by expressions $\Delta T_{\text {smaller }}=\min \left\{T_{h 1}-T_{c 2}, T_{h 2}-T_{c 1}\right\}$ and $\Delta T_{\text {larger }}=\max \left\{T_{h 1}-T_{c 2}, T_{h 2}-T_{c 1}\right\}$ (Fig. 2). In the second case, the following is applied $\Delta T_{\text {smaller }}=\min \left\{T_{h 1}-T_{c 1}, T_{h 2}-T_{c 2}\right\}$ and $\Delta T_{\text {larger }}=\max \left\{T_{h 1}-T_{c 1}, T_{h 2}-T_{c 2}\right\}$ (Fig. 5). However, it should be noted that in the sense of the Eq. (5) the value of the variable that can only be assigned to the double-tube countercurrent heat exchanger is calculated. By analysis of Eqs. (5) and (9), it can be found that $\Delta T_{\mathrm{ln}}=\mathrm{LMTD}$ only in the case of the double-tube countercurrent heat exchanger.

The variables defined by Eqs. (7) and (8) apply in particular to the determination of the variable $F$, while $F=\mathrm{f}\left(P_{c}, R_{c}\right)$, and $F \in\langle 0.0 ; 1.0\rangle$. The value of NTUmin belonging to the double-tube countercurrent heat exchanger is always obtained $\left(\mathrm{NTU}_{\min C}\right)$ if the variable $F$ is multiplied by the variable $\mathrm{NTU}_{\min }[7]$, [8].

\section{Mean temperature difference}

The information about the value of the expression $\bar{k} A$, that occurs in the rate equation of heat transfer $\dot{Q}=\bar{k} A \overline{\Delta T}$, is important to determine the heat transfer area. The knowledge of the mean temperature difference $(\overline{\Delta T})$ is the key for determining the value of the product $\bar{k} A$. Eq. (1) is a generally valid equation which has to satisfy any recuperative heat exchanger. According to this equation, the general equation can be written to calculate the mean temperature difference for any recuperative heat exchanger, i.e., Eq. (10):

$$
\overline{\Delta T}=\theta\left(T_{h 1}-T_{c 1}\right)=F \Delta T_{\mathrm{ln}}=\frac{P_{\min }\left(T_{h 1}-T_{c 1}\right)}{N T U_{\min }}=\frac{\left(T_{h 1}-T_{c 1}\right) F P_{\min }\left(1-R_{\min }\right)}{\ln \left[\left(1-R_{\min } P_{\min }\right) /\left(1-P_{\min }\right)\right]} .
$$




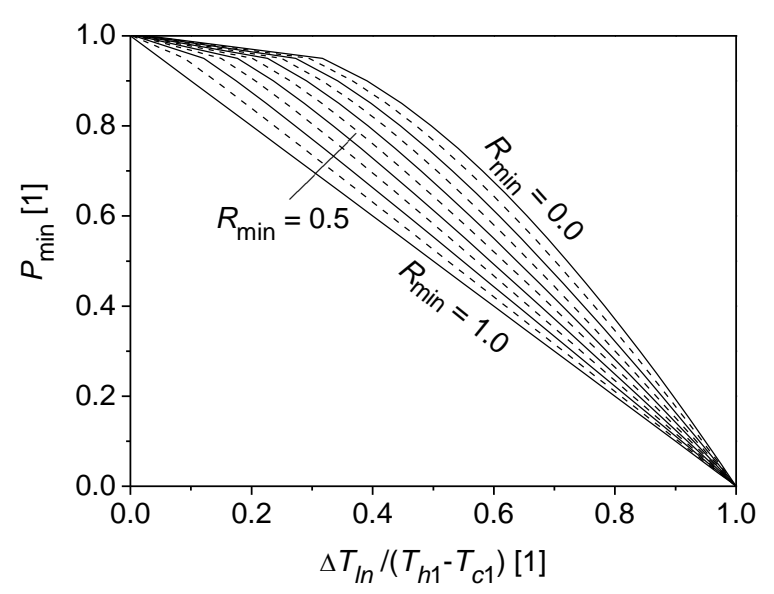

Fig. 3 The dependence of $P_{\min }$ on $\Delta T_{l n} / T_{h 1}-T_{c 1}$ for the double-tube countercurrent heat exchanger.

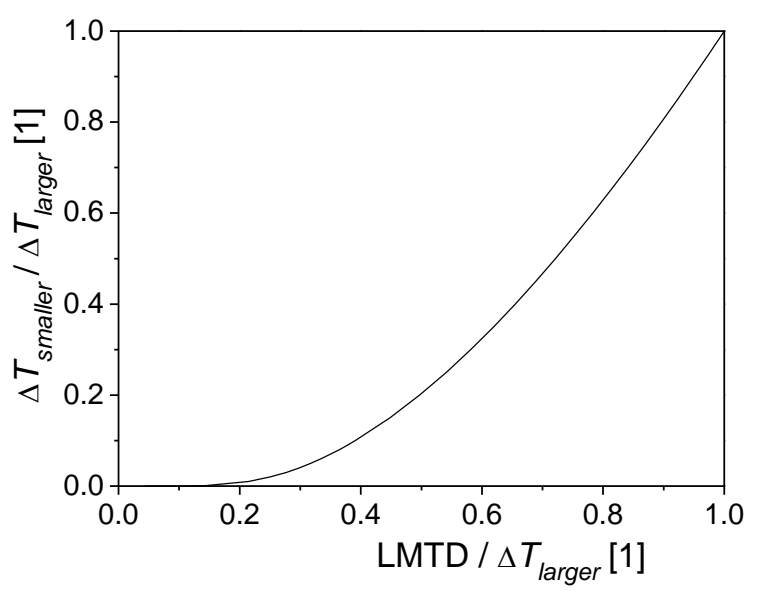

Fig. 4 The dependence of $\Delta T_{\text {smaller }} / \Delta T_{l \text { arg } \mathrm{er}}$ on LMTD $/ \Delta T_{\text {larger }}$ for the double-tube countercurrent and the double-tube concurrent heat exchanger.

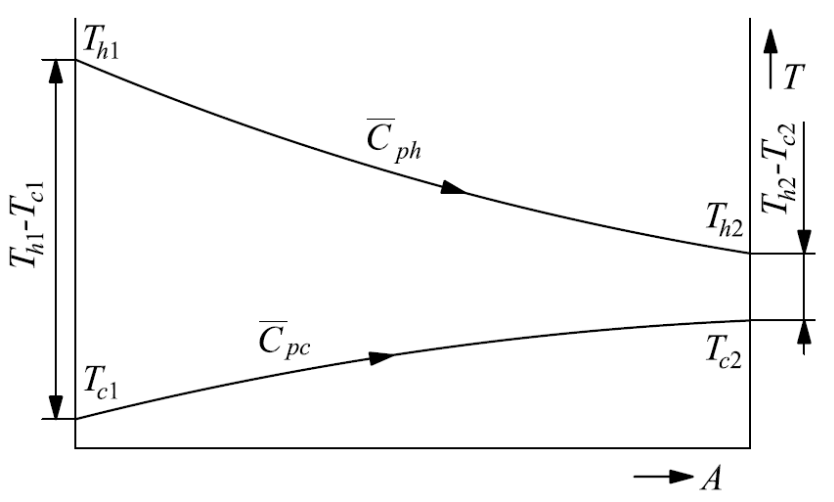

b) Temperature profile.

a) Schematic representation.

Fig. 5 The schematic representation of the double-tube cocurrent heat exchanger.

Fig. 6, applicable to each recuperative heat exchanger, can be obtained based on this equation and in the sense of above mentioned.

In some cases, the calculation of $\Delta T_{l n}$ by Eq. (5) may be replaced by the following equation:

$$
\Delta T_{\ln }=\left[\left(T_{h 1}-T_{c 2}\right)+\left(T_{h 2}-T_{c 1}\right)\right] / 2 .
$$

The same applies to LMTD which appears in Eq (9). Then the following equation can be written:

$$
\begin{gathered}
\mathrm{LMTD}=\left(\Delta T_{\text {larger }}+\Delta T_{\text {smaller }}\right) / 2, \text { alternatively, } \\
\mathrm{LMTD} / \Delta T_{\text {larger }}=\left(1+\Delta T_{\text {smaller }} / \Delta T_{\text {larger }}\right) / 2,
\end{gathered}
$$

in the sense of which the graphical dependence shown in Fig. 7 is obtained. A condition for using these three equations can be specified with reference to Fig. 8, which is obtained by joining Figs. 4 and 7. If the following applies: $0.5<\Delta T_{\text {smaller }} / \Delta T_{\text {larger }}<1.0$, Eqs. (11), (12), and (13) can be used for calculating $\Delta T_{l n}$, or LMTD. In this case, the error will not be more than $4.0 \%$. This is also in accordance with [9] and [10]. 
Using variables defined by Eqs. (7) and (8), Eq. (11) may be rewritten as follows:

$$
\frac{\Delta T_{l n}}{T_{h 1}-T_{c 1}}=\frac{2-P_{c}-P_{h}}{2}=\frac{2-P_{c}\left(1+R_{c}\right)}{2}=\frac{2-P_{h}\left(R_{h}+1\right)}{2} .
$$

This equation is similar to Eq. (6). For completeness, according to Eq. (1), and taking into account the above, the following equation can also be written:

$$
\begin{gathered}
\theta=\frac{\overline{\Delta T}}{T_{h 1}-T_{c 1}}=\frac{F \Delta T_{\mathrm{ln}}}{T_{h 1}-T_{c 1}}=\frac{P_{\text {min }}}{\mathrm{NTU}_{\min }}=\frac{F\left[2-P_{\min }\left(R_{\min }+1\right)\right]}{2}, \text { alternatively, } \\
\overline{\Delta T}=\theta\left(T_{h 1}-T_{c 1}\right)=F \Delta T_{\mathrm{ln}}=\frac{P_{\text {min }}\left(T_{h 1}-T_{c 1}\right)}{N T U_{\min }}=\frac{\left(T_{h 1}-T_{c 1}\right) F\left[2-P_{\min }\left(R_{\min }+1\right)\right]}{2} .
\end{gathered}
$$

It must be remembered that Eqs. (11) to (16) can be used only if the above condition is met, i.e., $0.5<\Delta T_{\text {smaller }} / \Delta T_{\text {larger }}<1.0$.

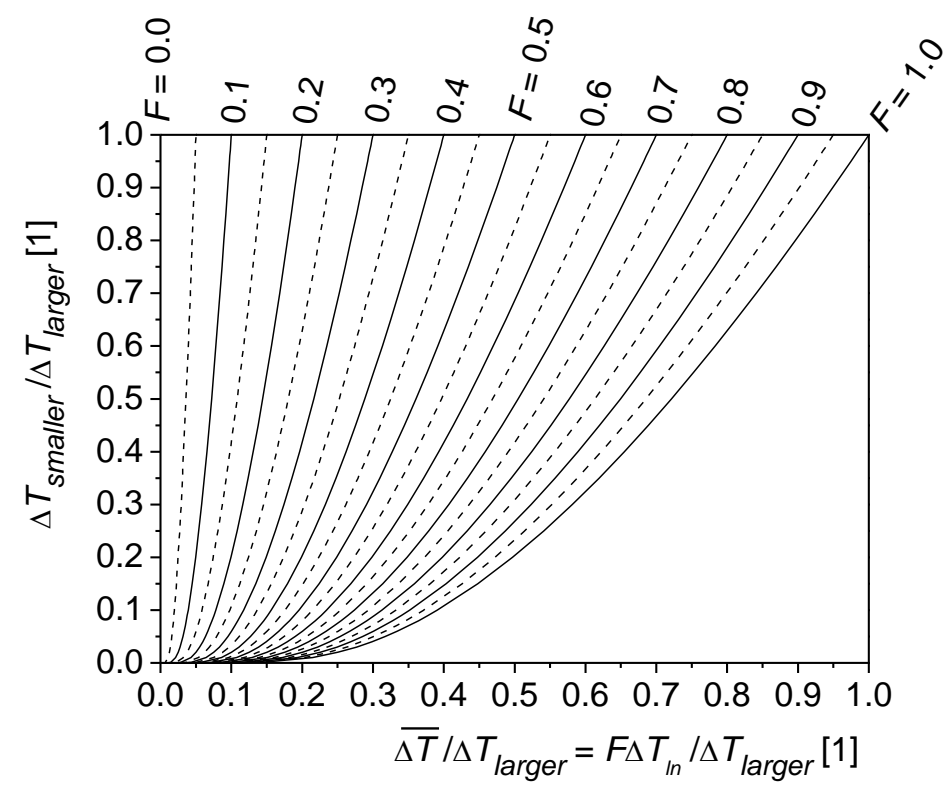

Fig. 6 The dependence of $\frac{\Delta T_{\text {smaller }}}{\Delta T_{l \text { arger }}}$ on $\frac{\overline{\Delta T}}{\Delta T_{\text {larger }}}$ for any recuperative heat exchanger, where $\Delta T_{\text {smaller }}=\min \left\{T_{h 1}-T_{c 2}, T_{h 2}-T_{c 1}\right\}$,
$\Delta T_{\text {larger }}=\max \left\{T_{h 1}-T_{c 2}, T_{h 2}-T_{c 1}\right\}$.

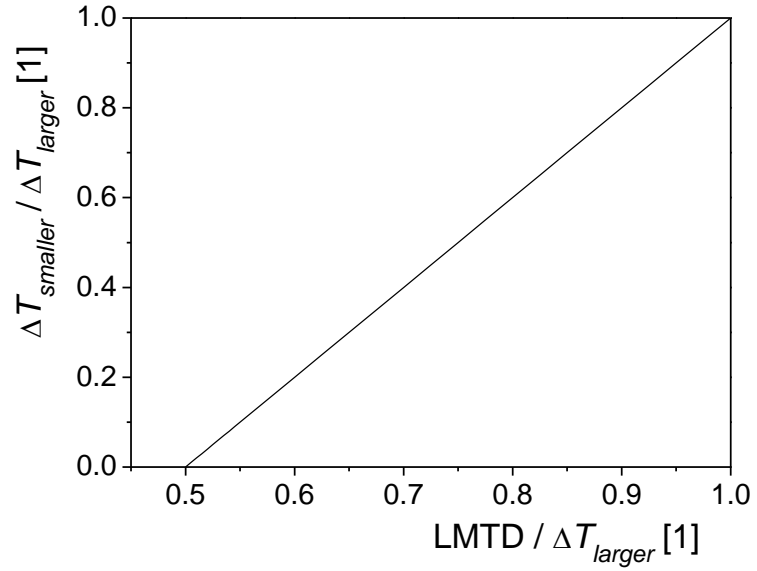

Fig. 7 The dependence of $\Delta T_{\text {smaller }} / \Delta T_{\text {larger }}$ on $\quad \mathrm{LMTD} / \Delta T_{\text {larger }}$ for the double-tube countercurrent and the double-tube cocurrent heat exchanger if $\frac{\Delta T_{\text {smaller }}}{\Delta T_{\text {larger }}} \in(0.5 ; 1.0\rangle$.

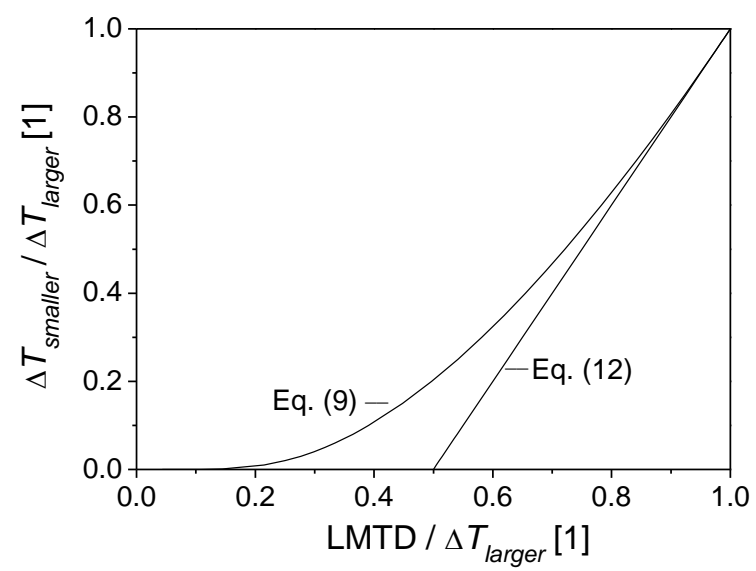

Fig. 8 The dependence of $\Delta T_{\text {smaller }} / \Delta T_{l \text { arg } \text { er }}$ on LMTD $/ \Delta T_{\text {larger }}$ for the double-tube countercurrent and the double-tube cocurrent heat exchanger. 


\section{Dimensionless mean temperature difference in the special cases of heat transfer}

Eq. (1) can be applied to any recuperative heat exchanger. However, in special cases, there is a problem that the value of one of the key variables (e.g., $\theta$ ) cannot be explicitly expressed from this equation. Figs. 9 to 12, which show the temperature profiles of heat exchangers, represent these special cases.

The first special case is the situation when the mean heat capacities of both streams are identical (Fig. 9). If $\bar{C}_{p h}=\bar{C}_{p s}$ (i.e., $R_{\text {min }} \rightarrow 1$ ), any stream heat capacity can be selected as $\bar{C}_{p \text { min }}$ (i.e., $\bar{C}_{p \text { min }}=\bar{C}_{p h}$, or $\bar{C}_{p \min }=\bar{C}_{p s}$ ). In this case, Eq. (10) can be adapted to this form:

$$
\lim _{R_{\min } \rightarrow 1} \theta=\frac{\overline{\Delta T}}{T_{h 1}-T_{c 1}}=\frac{F \Delta T_{\mathrm{ln}}}{T_{h 1}-T_{c 1}}=\frac{P_{\min }}{\mathrm{NTU}_{\min }}=F\left(1-P_{\min }\right),
$$

and in this case, $\Delta T_{\mathrm{ln}}$ is determined from the equation $\Delta T_{\mathrm{ln}}=\left(T_{h 1}-T_{c 2}\right)=\left(T_{h 2}-T_{c 1}\right)$.

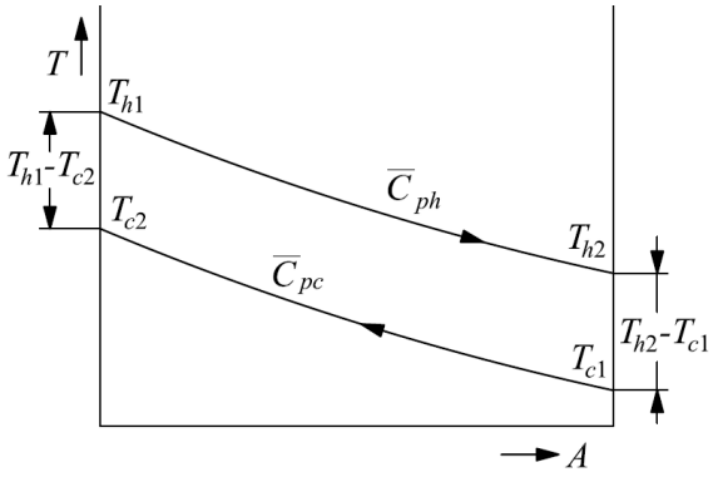

Fig. 9 The temperature profile scheme for the double-tube countercurrent heat exchanger without the phase change if $R_{\min } \rightarrow 1.0$.

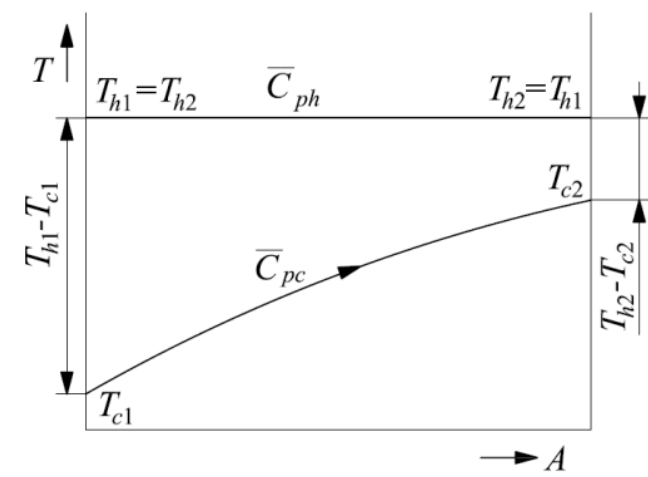

Fig. 10 The temperature profile scheme for the heat exchanger with the phase change occurring on the hot medium side (vapor condensation at the constant temperature).

Another special case corresponds to a situation where one of the mean heat capacity is infinitely large, i.e., $\lim _{T_{h 2}-T_{h 1} \rightarrow 0} \bar{C}_{p h}=\dot{m}_{h} \bar{c}_{p h}=\frac{\dot{m}_{h} \Delta_{\text {cond }} h\left(T_{h}\right)}{T_{h 2}-T_{h 1}}=\infty \quad$ (vapor condensation at constant temperature $T_{h 2}=T_{h 1}=T_{h}$, Fig. 10), or $\lim _{T_{c 2}-T_{c 1} \rightarrow 0} \bar{C}_{p c}=\dot{m}_{c} \bar{c}_{p c}=\frac{\dot{m}_{c} \Delta_{\text {evap }} h\left(T_{c}\right)}{T_{c 2}-T_{c 1}}=\infty$ (liquid boiling at constant temperature $T_{c 2}=T_{c 1}=T_{c}$, Fig. 11). It then means that $R_{\min } \rightarrow 0$. In this case, Eq. (1) can be easily adjusted to the form $\theta=\frac{\overline{\Delta T}}{T_{h 1}-T_{c 1}}=\frac{F \Delta T_{\mathrm{ln}}}{T_{h 1}-T_{c 1}}=$ $=\frac{P_{\text {min }}}{\mathrm{NTU}_{\text {min }}}=\frac{F P_{\text {min }}}{-\ln \left(1-P_{\text {min }}\right)}$. However, the reason for classifying these cases as special is that, in these cases, $F$ is always equal to one, i.e., $F=1$ [7]. This can also be demonstrated using the universal equation for calculating the heat efficiency of a recuperative heat exchanger [7], [11]. Solving this universal equation gives: $Z=1$ and $\mathrm{NTU}_{\min }=\ln \left(\frac{1}{1-P_{\min }}\right)$. This means that in the equation for calculating the dimensionless mean temperature difference $(\theta)$, it must be true that $F=1$. So for the second special case, the equation may be written: 


$$
\lim _{R_{\min } \rightarrow 0} \theta=\frac{\overline{\Delta T}}{T_{h 1}-T_{c 1}}=\frac{\Delta T_{\mathrm{ln}}}{T_{h 1}-T_{c 1}}=\frac{P_{\min }}{\mathrm{NTU}_{\min }}=\frac{P_{\min }}{-\ln \left(1-P_{\min }\right)} .
$$

If the condition $0.5<\Delta T_{\text {smaller }} / \Delta T_{\text {larger }}<1.0$ is fulfilled, Eq. (18) may be replaced by the following form of equation:

$$
\lim _{R_{\min } \rightarrow 0} \theta=\frac{\overline{\Delta T}}{T_{h 1}-T_{c 1}}=\frac{\Delta T_{\mathrm{ln}}}{T_{h 1}-T_{c 1}}=\frac{P_{\min }}{\mathrm{NTU}_{\min }}=\frac{2-P_{\min }}{2} .
$$

This equation is obtained similarly to Eq. (18) but the Eq. (16) is the source equation for its creation. By these equations, Fig. 13 can be constructed.

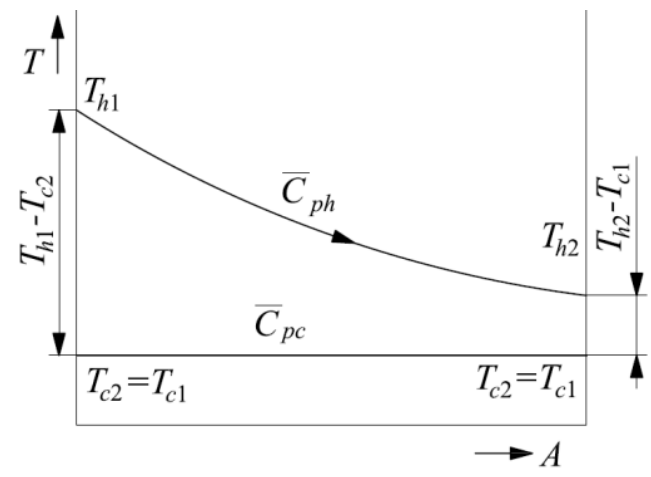

Fig. 11 The temperature profile scheme for the heat exchanger with the phase change occurring on the cold medium side (liquid boiling at the constant temperature).

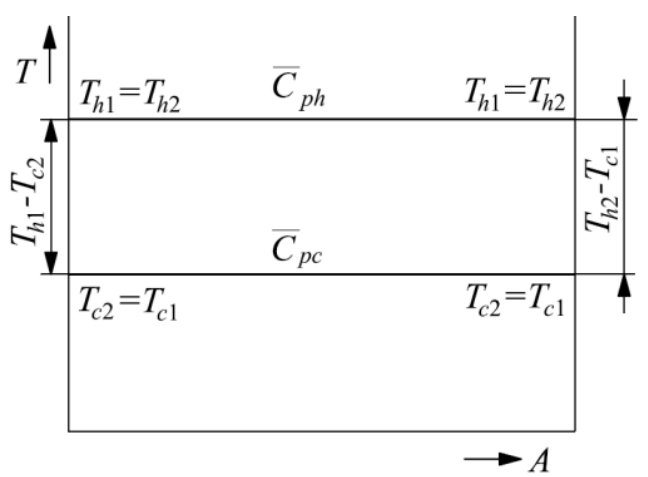

Fig. 12 The temperature profile scheme of the heat exchanger with the phase change of both media (vapor condensation and liquid boiling at the constant temperature).

In Eqs. (18) and (19), the variable $\Delta T_{\mathrm{ln}}$ is again determined from Eqs. (5) and (11). If Eq. (18) represents condensation, then $\Delta T_{\mathrm{ln}}=\left[T_{c 1}-T_{c 2}\right] / \ln \left[\left(T_{h}-T_{c 2}\right) /\left(T_{h}-T_{c 1}\right)\right]$, otherwise, in the case of evaporation $\Delta T_{\mathrm{ln}}=\left[T_{h 1}-T_{h 2}\right] / \ln \left[\left(T_{h 1}-T_{c}\right) /\left(T_{h 2}-T_{c}\right)\right]$. In the case of Eq. (19), it applies similarly $\Delta T_{\mathrm{ln}}=\frac{\left[2 T_{h}-\left(T_{c 2}+T_{c 1}\right)\right]}{2}$ (condensation) and $\Delta T_{\mathrm{ln}}=\frac{\left[\left(T_{h 1}+T_{h 2}\right)-2 T_{c}\right]}{2}$ (evaporation).

The penultimate situation (the third special situation) that may occur is that the mean heat capacities of the streams are the same as in the case represented by Eq. (17) but infinitely large (i.e., $\lim _{T_{h 2}-T_{h 1} \rightarrow 0} \bar{C}_{p h}=\lim _{T_{c 2}-T_{c 1} \rightarrow 0} \bar{C}_{p c}=\infty$ ). In such a case, when $T_{h 2}=T_{h 1}=T_{h} \quad$ (vapor condensation at $T=$ const.) and $T_{c 2}=T_{c 1}=T_{c}$ (liquid boiling at $T=$ const.) (Fig. 12) the equation for calculating $\Delta T_{\mathrm{ln}}$ has the form $\Delta T_{\mathrm{ln}}=T_{h 1}-T_{c 1}$ and here also applies $P_{\min } \rightarrow 0$, $R_{\min } \rightarrow 1$, and $\mathrm{NTU}_{\text {min }}=\mathrm{f}\left(P_{\min }, R_{\min }, p_{p}\right) \rightarrow 0$. Using the universal equation for calculating the heat efficiency of the recuperative heat exchangers [7], [11] it is again possible to prove that in the limit $P_{\min } / \mathrm{NTU}_{\min }=1$ if $P_{\min } \rightarrow 0$. If this is to be true, then in Eq. (10) it must be $F=1$. In this penultimate situation, Eq. (1) takes a simple form given by the equation:

$$
\lim _{P_{\min } \rightarrow 0} \theta=\frac{\overline{\Delta T}}{T_{h 1}-T_{c 1}}=\frac{\Delta T_{\mathrm{ln}}}{T_{h 1}-T_{c 1}}=\frac{P_{\min }}{\mathrm{NTU}_{\min }}=1 .
$$

The double-tube countercurrent and the double-tube cocurrent heat exchanger represent the last special situation. For these heat exchangers, the mean temperature difference 
( $\overline{\Delta T}$ ) for different combinations of $P_{\min }$ and $R_{\min }$ is always determined by the equation $\overline{\Delta T}=F \Delta T_{\mathrm{ln}}=\mathrm{LMTD}$ [10]. This justifies their inclusion among special cases. Taking into account the above, the equation for calculating the dimensionless mean temperature difference $(\theta)$ can be written as:

$$
\theta=\frac{\overline{\Delta T}}{T_{h 1}-T_{c 1}}=\frac{\mathrm{LMTD}}{T_{h 1}-T_{c 1}}=\frac{P_{\text {min }}}{\mathrm{NTU}_{\min }}=\frac{\Delta T_{\text {larger }}\left[1-\Delta T_{\text {smaller }} / \Delta T_{\text {larger }}\right]}{\left(T_{h 1}-T_{c 1}\right) \ln \left[1 /\left(\Delta T_{\text {smaller }} / \Delta T_{\text {larger }}\right)\right]} .
$$

If the condition $0.5<\Delta T_{\text {smaller }} / \Delta T_{\text {larger }}<1.0$ is fulfilled, the following equation may be used instead of Eq. (21) to calculate $\theta$ :

$$
\theta=\frac{\overline{\Delta T}}{T_{h 1}-T_{c 1}}=\frac{\mathrm{LMTD}}{T_{h 1}-T_{c 1}}=\frac{P_{\min }}{\mathrm{NTU}_{\min }}=\frac{\Delta T_{\text {larger }}\left[1+\Delta T_{\text {smaller }} / \Delta T_{\text {larger }}\right]}{\left(T_{h 1}-T_{c 1}\right) 2} .
$$

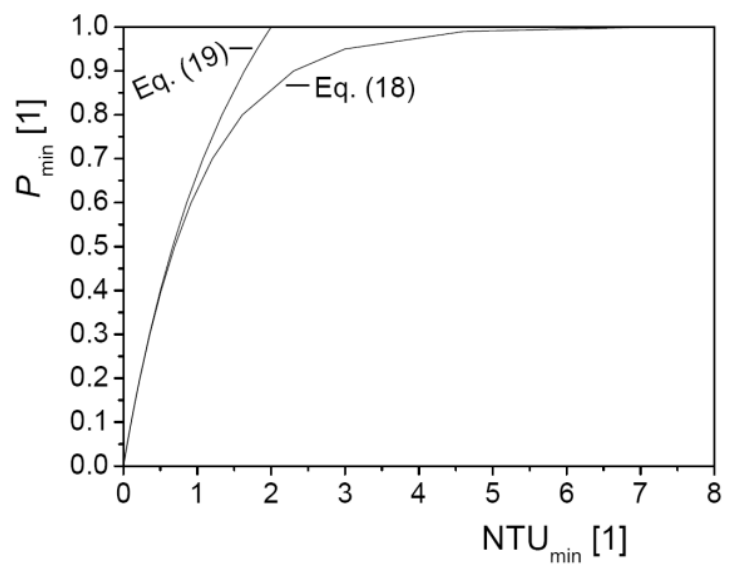

Fig. 13 The dependence of $P_{\text {min }}$ on $\mathrm{NTU}_{\text {min }}$ for any recuperative heat exchanger if $R_{\min } \rightarrow 0.0$.

Eqs. (17) to (22) allow the calculation of the dimensionless mean temperature difference, or other variables (for example, $\mathrm{NTU}_{\min }=\bar{k} A / \bar{C}_{p \min }$ ), in special cases if the conditions under which these equations have been compiled are fulfilled. If $F=1$ (i.e., $\overline{\Delta T}=\Delta T_{\mathrm{ln}}$ ), the general rate equation of heat transfer (i.e., $\dot{Q}=\bar{k} A \overline{\Delta T}$ ) corresponds to the form:

$$
\dot{Q}=\bar{k} A \Delta T_{\ln },
$$

from which the value of the expression $\bar{k} A$ can be determined. This equation may be applied to the cases represented by Eqs. (18) to (20), as well as in the case of double-tube countercurrent heat exchanger. In the case of the double-tube cocurrent heat exchanger, the following equation must be used $\dot{Q}=\bar{k}$.A.LMTD. In all other cases (i.e., $F \neq 1$ ), the calculation of the recuperative heat exchangers can be based on Eq. (1) if $F$ is known.

\section{CONCLUSION}

The main aim of the article is to state that in special cases it is possible to calculate any recuperative heat exchanger (key variables) without knowing the operating characteristic of the given heat exchanger. These cases are represented by Eqs. (18) to (22). Without the operating characteristic, the calculation of a heat exchanger is generally not possible to carry out by Eqs. (1) and (17). However, the knowledge of the operating characteristic is not necessary in certain circumstances (when $F \cong 1$ ) [7]. Knowing the values of the key variables allows to determine the value of the expression $\bar{k} A$. By determining the value 
of this expression, the calculation of the recuperative heat exchanger (calculation of the heat transfer area) then becomes relatively problem-free.

General equation, Eq. (1), which must comply with any recuperative heat exchanger, is also presented in this article. This equation, as well as Fig. 6, is particularly useful for checking data obtained from the experimental measurements.

\section{ACKNOWLEDGEMENTS}

This research did not receive any specific grant from funding agencies in the public, commercial, or not-for-profit sectors.

\section{NOMENCLATURE}

Latin Letters

$\begin{array}{llll}A & - \text { heat transfer area }\left[\mathrm{m}^{2}\right] & & \text { difference }[\mathrm{K}] \\ c_{p} & - \text { specific heat capacity at constant } & \dot{m} & - \text { mass flow rate }[\mathrm{kg} / \mathrm{s}] \\ & \quad \text { pressure }[\mathrm{J} /(\mathrm{kgK})] & \text { NTU } & \text { - number of transfer units }[1] \\ C_{p} & - \text { heat capacity flow rate at constant } & P & - \text { dimensionless temperature } \\ & \text { pressure }[\mathrm{W} / \mathrm{K}] & & \text { change }[1] \\ F & - \text { logarithmic mean temperature } & \dot{Q} & - \text { heat flow rate }[\mathrm{W}] \\ & \quad \text { difference correction factor }[1] & R & - \text { heat capacity rate ratio }[1] \\ k & - \text { overall heat transfer coefficient } & T & \text { - temperature }[\mathrm{K}] \\ & {\left[\mathrm{W} /\left(\mathrm{m}^{2} \mathrm{~K}\right)\right]} & Z & - \text { auxiliary parameter }[1]\end{array}$

LMTD - logarithmic mean temperature

Greek Letters

\begin{tabular}{|c|c|c|c|}
\hline$\Delta_{\text {cond }} h(T)$ & $\begin{array}{l}\text { - enthalpy of condensation } \\
\text { at temperature } T[\mathrm{~J} / \mathrm{kg}]\end{array}$ & $\Delta T_{l n}$ & $\begin{array}{l}\text { - logarithmic mean temperature } \\
\text { difference for double-tube }\end{array}$ \\
\hline$\Delta_{\text {evap }} h(T)$ & $\begin{array}{c}\text { - enthalpy of evaporation } \\
\text { at temperature } T[\mathrm{~J} / \mathrm{kg}]\end{array}$ & $\varepsilon$ & $\begin{array}{l}\text { countercurrent heat exchanger }[\mathrm{K}] \\
\text { - dimensionless temperature change }\end{array}$ \\
\hline$\Delta T$ & $\begin{array}{l}\text { - the temperature difference } \\
\text { between two flowing media } \\
\text { at the end or the start of the heat } \\
\text { transfer area }[\mathrm{K}]\end{array}$ & $\begin{array}{l}\Phi \\
\theta\end{array}$ & $\begin{aligned} & {[1] } \\
- & \text { heat efficiency [1] } \\
- & \text { dimensionless mean temperature } \\
& \text { difference }[1]\end{aligned}$ \\
\hline$\overline{\Delta T}$ & - mean temperature difference $[\mathrm{K}]$ & & \\
\hline
\end{tabular}

Subscripts

$\begin{array}{ll}\text { B } & - \text { point } \\ i & - \text { i-th medium } \\ \text { smaller } & - \text { smaller } \\ \text { larger } & - \text { larger } \\ \underset{\max }{\min } & - \text { stronger stream, maximum } \\ { }_{-} & - \text {weaker stream, minimum } \\ 1 & - \text { mean value } \\ & - \text { weaker stream }\end{array}$
2 - stronger stream
- at the inlet
- at the outlet
- hot medium
c - cold medium
C - double-tube countercurrent heat exchanger
$\mathrm{CO}$ - double-tubecocurrent heat exchanger




\section{REFERENCES}

[1] Bowman R. A., Mueller A. C., Nagle W.M. "Mean temperature difference in design", , ASME Transaction 62, 1940.

[2] Kays W. M., London A. L. "Compact heat exchangers", 2nd ed., New York , McGraw-Hill Book Co., 1964.

[3] Mueller A. C., in Rohsenow W. M., Hartlett J. P. "Handbook of heat transfer", Sec. 18., Heat exchangers, New York, McGraw-Hill, pp. 1 - 113, 1973.

[4] Roetzel W., Spang B. "Vefbessertes Giagramm zur Berechnung von Wänneüberttragern”, Wärme-unf Stoffübertragung, 25, pp. 259 - 264, 1990.

[5] Jelemenský K., Šesták J., Žitný R.: "Tepelné pochody", 2. vydanie, Bratislava: Vydavatel'stvo STU v Bratislave, 2004. (in Slovak)

[6] Gužela Š., Dzianik F., Juriga M., Kabát J.: "Shell and tube heat exchanger - The heat transfer area design process", Strojnícky časopis - Journal of Mechanical Engineering 67 (2), pp. 13 - 24, 2017. DOI: 10.1515/scjme-2017--0014.

[7] Gužela Š., Dzianik, F. "Some facts resulting from the key variables used in the description of the recuperative heat exchangers", Strojnícky časopis - Journal of Mechanical Engineering 68 (3), pp. 249 - 260, 2018., DOI: 10.2478/scjme-2018-0038.

[8] VDI Heat Atlas, Second Edition, Springer-Verlag Berlin Heidelberg, 2010. ISBN 978-3-540-77876-9.

[9] Bafrnec M., Báleš V., Langfelder I., Longauer J. "Chemické inžinierstvo I.”, 1. vydanie, 440 pp., Vydavatel'stvo MALÉ CENTRUM, 1999. ISBN 80-967064-3-8 (in Slovak)

[10] Lodes A., Langfelder I. "Procesy a zariadenia 1", 1. Vydanie, 688 pp., Vydala ALFA 1988. ISBN 80-05-00150-9 (in Slovak)

[11] Schneller J., Hlavačka V. "Význam termickej účinnosti při výpočtech jednoduchých i složitějších teplosměnných systémů”, Strojírenství 6 (22), 1972. (in Slovak) 